\title{
Parent and ethnographer of other children
}

By David Poveda (Universidad Autónoma de Madrid and University of Wales, Lampeter)

In this article I examine the role my parental identity and my daughter's presence in the field played in the relationship I established with a group of Gitano (Spanish Roma) children and their families. This study was conducted as part of a linguistic ethnography focused on children's peer interactions and social organisation during their informal daily activities. The discussion addresses the more general issue of how researchers from various social disciplines incorporate their own children into the research process.

Conducting ethnographic research on children raises a number of methodological and ethical challenges that have been part of the anthropology of childhood since it was established as an independent subfield (Hardman 1973). At the centre of these debates there are two intertwined problems: (a) the inherent asymmetry that is part of the adult researcher-child participant relationship, and (b) that access to children is always mediated by other adult gatekeepers who may be especially protective of children as research subjects. There are aspects of these issues that are common to ethnographic research and participant observation in general, regardless of the group being studied (e.g. Abu-Lughod 1988, Aull Davies 1999, Okely 1983). Yet different authors also claim that doing participant observation with children raises specific problems not present in other research scenarios. Several of these issues have already been explored in a number of particularly methodologically reflexive works in anthropology, sociology and other fields (e.g. Christensen and James 2000, Greene and Hogan 2005).

Taking these debates as a starting point, in this article I want to focus on a particular configuration of social relationships that is frequently present in studies of childhood, whether ethnographic or not: the role that the researcher's own children can play in research about childhood. I outline how this question has been historically addressed in various disciplines and in ethnographic studies involving children. This review is used as the context to discuss the identity processes and practical-ethical dilemmas that were part of my own ethnographic research project in which my daughter played a key role in my access to the peer interactions of a group of Spanish Gitano children (Gitano is the common term used for self-reference by the majority of Spaniards of Roma/Gypsy origin). Therefore, this paper has two goals. First, to review and discuss critically the roles that have been assigned to researcher's offspring in the social study of children. Second, drawing on my experience and that of other colleagues, to examine the potential benefits and problems associated with other collateral roles offspring may assume in the research process. This analysis will be used to introduce questions and raise a number of possibilities that have received little attention in the methodological literature. 


\section{Offspring as subjects and participants}

In this section I present a number of roles that offspring have played in research. The review is not exhaustive and only highlights key turning points and authors in relation to different alternatives. My approach will also be somewhat historical and I will examine how different possibilities have been contemplated in the various disciplines that have configured modern studies of childhood. I include several quotations which should be seen as "data" for this part: as direct excerpts of how different authors have construed the role of offspring in research.

The first and most discussed alternative involves researchers utilising their own children as main participants/subjects in their studies of childhood. This alternative has obvious advantages. First, by studying his or her own children, the researcher avoids dealing with the problem of negotiating access to children with "third party gatekeepers". Second, and this is the factor that has made it especially attractive, it reduces greatly the difficulties and costs involved in gathering sustained and detailed observations of children's evolving daily behaviour. These advantages are at the heart of the very first modern studies of childhood and served to establish the first methodological tools to study children: "baby and child diaries". Charles Darwin, as part of the questions that developed with his general theory of the evolution of species, was interested in several aspects of infant behaviour and eventually began taking systematic diary observations of his own son, which led to a monograph on the subject (Bradley 1989). Subsequently, diaries of offspring became the main tool to study children and human development. This occurred as childhood became a topic of interest in the human sciences (especially in psychology), since observations about human development were seen as important to address basic epistemological and theoretical questions.

Within psychology, the diary as a research tool reached its full elaboration through the work of Jean Piaget during the first half of the twentieth century. Piaget provided very careful descriptions of his own children's activity - which are still discussed today and incorporated these into a full theoretical analysis of human development. Gopnik, Meltzoff and Kuhl (1999:15) summarise his contribution in the following terms:

In the thirties Piaget began to record the lives of his own three infant children, Jacqueline, Lucienne, and Laurent. There have been baby diaries before and since, but there is nothing like the Piaget diaries. They record in minute, crystalline detail the significant patterns in the apparently formless behaviour of very young babies. (...) The observations of the babies are embedded in an alternately impenetrable and brilliantly insightful theoretical apparatus.

However, as psychology developed more firmly into a quantitative and positivistic discipline, child diaries and case studies lost force as the preferred methodology in favour of more experimental procedures that used systematically selected samples of children. Consequently, data gathering began to rely less heavily on the experimenter's own offspring and further methodological or ethical discussions of this approach did not develop. An exception to this trend is found in studies of language development, where continuous and detailed documentation of children's language is absolutely necessary to address the key research problems in this field. Consequently, there is a firmly established tradition in studies of language acquisition (in psychology and linguistics) of small/single case studies of children's language development, in which the main subject of the study is the researcher's own child. Often, these 
observational studies of language development are accompanied by data gathering techniques (sampling, recording, etc.) and analytical strategies (statistical analysis, longitudinal comparisons, etc.) designed to meet positivist definitions of validity and generalisation. In contrast, the ethical or theoretical implications of this strategy are not usually foregrounded in case studies of language development. Nevertheless, this rationale led to the first strong critiques from linguistic anthropology in relation to the use of researcher's children (or closely related individuals) as research subjects. Ochs and Schieffelin (1984), while articulating their language socialisation paradigm, raise some of the consequences that focusing on children who are personally and socially close to the researcher has for mainstream psychological thinking:

That the researcher, reader and subjects of study tend to have in common a white middle-class literate background has had several consequences. For example, by and large, the psychologist has not been faced with the problem of cultural translation, as has the anthropologist. There has been a tacit assumption that readers can provide the larger cultural framework for making sense out of the behaviours documented, and, consequently, the cultural nature of the behaviours and principles presented have not been explicit. (Ochs and Schieffelin 1984:283-284)

This was a crucial critique that helped promote a new generation of cross-linguistic studies in which researchers gathered data on language acquisition processes outside their own communities. However, implicit in this observation and explicit in the language socialisation paradigm there is also an ontological conflict between, on the one hand, studying individual subjects as isolated developmental units - which is the dominant rationale in developmental psychology - and a focus on cultural patterns where the individual is embedded in a social network - which is the dominant rationale of socio-cultural approaches and anthropology. Within the language socialisation paradigm, this move is fundamentally methodological and places ethnography in a privileged position. Ochs and Schieffelin's (1984) call is to provide ethnographic context and cultural meaning to observations of linguistic (or other types of) behaviour. According to traditional notions of fieldwork this may be "easier" to accomplish in a community different from the researcher's, where the familiar becomes immediately strange and explicitly requires interpretation-translation, but it certainly can (or even should be) accomplished when analysing aspects of one's own cultural system. For example, in the case of studies of children's language, some authors have managed to study their own children's discursive practices while still placing these in cultural context (e.g. Greenwood 1998, Hoyle 1998).

In contrast to these debates within studies of language development, when the issue of studying one's own children is relocated more generally within ethnographic research new problems arise. To begin, it is never a question of studying "only" the researcher's own children, because even if offspring are the focal participants, fieldwork will document their participation in a variety of settings (e.g. home, school, playgrounds, etc.) and their interactions with various actors (e.g. teachers, other family members, peers, etc.) and access negotiations will always involve these other parties. Also, whether focused on children or not, ethnographic fieldwork involves strategies, commitments and definitions of social actors (who, among other things, are not labelled "subjects" but "participants") that are very different from standard social scientific positivist thinking. Consequently, within ethnographic studies of children there has been an explicit conceptual articulation of the meaning and implications that using one's own children as research participants may have. Adler and Adler (1996) 
provide a systematic exploration of the methodological, practical and ethical implications of this configuration. Drawing on their study of preadolescent peer culture in which their children and their social worlds became research topics, they label their strategy parent-as-researcher and see it as an "opportunistic" strategy that can capitalise on parent's complete membership role, locating it within the tradition of studies in which personal life becomes a topic of investigation and ethnography "encompasses a dual research-membership focus" (Adler and Adler 1996:36) similar to those of teacher-as-researcher or counsellor-as-researcher.

The parent-as-researcher strategy has not been received without critique. So far, the objections I have presented to the use that researchers make of their own children have been addressed in terms of practical and analytical advantages and disadvantages. Stated in these terms, it is possible to open up a dialectical dynamic where particular obstacles can be confronted or theoretical problems taken into consideration without globally questioning this choice of participant/subject. In contrast, for ethnographers of children the problems are not primarily practicaltheoretical, they are ethical. Corsaro (2005:57) in his review of research methods clearly states the problems:

The parent-as-researcher strategy (...) is one of the most widely critiqued methods of studying children. Parents can frequently face ethical and role conflicts in deciding which events are public and therefore available to be recorded as data versus which events are private and confined to the parental role. Additionally, traditional ethnographers attempt to see the world through the children's eyes and become a member of children's cultures as much as possible. Parents, on the other hand, cannot ethically cross the boundary between child and adult to become "one of the kids" because they are in an inherently supervisory position.

Ethical problems cannot be circumvented through straightforward technical modifications. Consequently, given the significance of the problems raised by Corsaro, within ethnographic studies of children, the dominant choice has been to avoid using one's own children even when these are "available" for the research questions under study. In this scenario it would seem that the case is relatively closed and there are not many other considerations to be made concerning the role of researcher's children in ethnographic fieldwork. A review of methodological discussions of ethnographic research on children suggests this is the case. Typically, authors present the parent-as-researcher approach, discuss the benefits and disadvantages of turning offspring into participants, and move on to other issues. From my perspective, this is a very unfortunate development because, even if offspring are not the central participants of the study, researcher's children are often present in the fieldwork process and these dynamics should be taken into consideration. For example, fieldwork projects that involve prolonged relocations often become a "family effort" and ethnographer's children are incorporated into the ethnographic text regardless of whether the study focuses on childhood or not (e.g. Scheper-Hughes 1993, Weiner 1988). The presence of the author's offspring and family is usually made visible in sections of the text such as acknowledgments, footnotes or afterwords, where anecdotal illustrations and personal accounts are introduced. For example, Annette Weiner's (1988) monograph on the Trobianders of Papua New Guinea begins each chapter with a quote from her daughter's diary, she is mentioned in the acknowledgments and her role in producing relevant data is made visible in footnotes: 
When a man decides that he wants a woman for his "good friend" he begins to send her small presents such as betel nuts and tobacco, using other young people as intermediaries. When my daughter Linda lived with me in Kwaibwanga, without my knowledge she acted as a messenger, relaying betel nuts and information between Ruth and Sylvester about their secret meeting plans. (Weiner 1988:70, footnote 6)

In fact, what makes ethnographic work peculiar in relation to other research methodologies and approaches is not whether researchers choose or do not choose to study their own children (offspring can also be tested, used in experiments, recorded and codified, etc.), but that the full range of personal relationships and processes that "surround" fieldwork affect the research process, the data that is produced and the type of interpretations that are possible. In other words, there are many other collateral roles that researchers' children can play in the research process. Glimpses of these roles are made visible in various ethnographic texts, but they do not seem to have been analysed reflexively in methodological terms - whereas, for example, the position of "ethnographer-as-daughter" along with the role of the researcher's father in field access has been discussed (Abu-Lughod 1988). In the second part of this article I am going to discuss some of these other roles researchers' children can play in ethnographic fieldwork, particularly when the focus of study is childhood. To do this I am going to present part of my own fieldwork experience, along with that of other colleagues who have shared their experiences with me, and focus especially on the identity process that may come into play when the research process defines a role for the researcher's offspring.

\section{Offspring in other research-related roles}

During the summer of 2001 I conducted a small linguistic ethnography of a group of Gitano children's spontaneous games and social interactions (e.g. Poveda 2006, Poveda and Marcos 2005). The study was conducted in a mid-sized city in Spain and especially in one neighbourhood of the locality where a large proportion of the Gitano community of the city lived. Data gathering involved common techniques in linguistic anthropology such as audio-video recordings, participant observation, interviews and collecting other documents. This study took place as part of a large project focused on Gitano children's linguistic and literacy practices in different out-of-school contexts.

Previously I had gathered data in an after-school and summer programme run by the local Gitano cultural association, and had expressed my interest in studying children's informal interactions outside these settings to the professionals of the organisation. A social worker from the association suggested that I go to certain parks in the neighbourhood where groups of children I already knew usually played. Thus, for several evenings I went to these parks to make preliminary observations and contacts. I took my (at the time) one year old daughter, Lorca, with me to these first scouting visits. This was done as a common-sense consideration and was not though-out as a methodological strategy: it simply seemed more natural for me to visit parks accompanied by my own child and there was no obvious reason to deprive my daughter of a walk to a park on a summer evening. However, this choice turned out to be quite successful and my daughter soon played an unexpected role in the research process and for my access to Gitano children and their peer interactions. Practically from the first visit the children who eventually became participants in my study remembered me from the summer-school programme that ran the previous year. More 
importantly, they were also immediately drawn to my daughter and wanted to play with her, push her stroller and walk her around and were, therefore, happy to have me around if that implied I was bringing my daughter. During the first days in which I visited the park and started to communicate to the children my interest in observing them, the children were more interested in incorporating my daughter (not me) in some way into their peer interactions and relations. In fact, in these very early stages of negotiating access, the children incorporated my daughter, despite her young age and limited interactive possibilities, into their play practices, as the field notes from these first days capture (translated from Spanish into English and using pseudonyms for the participants):

While they were playing Juan moved to say something "secretly" to Isabel and asked if she was going to tell me. A little later I asked Isabel what it was they wanted to tell me. The kids took me to a wall in the park and showed me what they had written with chalk on a brick wall:

ALORCA Lorca es de este parque tus amigos Juan y Isabel

[ALORCA Lorca is from this park your friends Juan and Isabel]

Later, Isabel told Juan that she liked to take care of Lorca a lot because they had never taken care of little children and she liked little kids. Then the rest of the children said that they also liked taking care of children. Meanwhile, Vanessa was constantly pulling up Lorca's suspender, which was falling off all the time. Susana [my wife] said "she is quite concerned about Lorca's appearance".

In other words, what initially simply seemed a practical arrangement that I had not really thought about much turned out to be a key resource in my relationship with these children. Seen from this perspective, in something of an inverse relationship from that discussed by Abu-Lughod (1988) in which her father played a key role in her incorporation into a Bedouin family, my daughter was a key factor in my access to these children. Lorca (misspelled as Alorca by the children) was never the main participant in this study, nor did my analysis ever focus on interactions with Lorca, and I eventually participated in the activities of these children without my daughter. Yet her presence defined the type of relationship I established with the children and the identities I had available to relate with them and their families.

This strategy and role distribution resonated with the one José Luis Linaza, a Spanish psychologist and ethnographer of children's play, developed much more systematically with his own son in his work on Pasiego children (Pasiegos are the inhabitants of a rural mountain region in the north of Spain), and his insights eventually became a referent in my own study. In a written personal communication about this process (January 28, 2008) he described his approach as follows (translated from Spanish):

When we started our trips to Cantabria to observe and study Pasiego children I offered my youngest son, Miguel, the possibility of coming with us. I thought that he would enjoy it and it would provide me with a very specific identity, the father of a new child in the school. It worked very well (...) Miguel participated in school activities with curiosity and interest, since the school was very different from his school in Madrid. He participated in games during recess. He even had a few conflicts with "pranksters" (they tried to lock him up in the bathroom) that he dealt with successfully, helped by his Pasiego friends. 
As far as my own project with Gitano children was concerned, to be able to conduct this study I also needed permission from the children's parents and adult care-takers. This permission is an ethical and legal requirement when minors are research participants (and was eventually granted in writing), but in the case of ethnographic fieldwork of this type, "permission" is also negotiated on a daily basis for various emerging events. I always consulted with the children's parents or grandparents (grandparents were often responsible for daily care while the children's parents were working) on matters such as whether we could cross a street to go to another park, whether I could drive them in my car to visit my university office or go to a burger shop, and so on. Most of these negotiations were favourable and, although they may appear as minor requests, they involved putting the children under my direct supervision and away from their parents/grandparents' immediate care, or allowed me to get involved in activities and spaces in which adults would normally not be present, such as inside a hut that the children built in the park.

Practically on every occasion I was explicitly reminded to take care of the children and to be careful - some hesitation was more than reasonable given that I was a relative stranger and each of these special activities involved something extraordinary in their daily routines and movements. These privileges and responsibilities were only granted because of my (apparent) trustworthiness as a competent adult to take care of the children. I believe this attribution of competence was intimately tied to the perception the adults had of me as a responsible parent. These perceptions were supposedly based on their own observations of my behaviour with my daughter and their children and grandchildren. Eventually, I learned to give an answer that seemed to be very satisfying to their call to carefulness: "(I'll take care of them) as if they were my daughter." In other words, a central element of my trustworthiness as an adult which allowed me to conduct research was, at least partially, the result of the projections on my adult persona that resulted from my observable relationship with my daughter. Further, taking care of children was a task that could be reciprocated between adults. Eventually, during the fieldwork process there were occasions when I left Lorca under the care of the adults of the focal family of the study while I had to go to work at the university (to attend meetings, exams, etc.). This was an arrangement that I used only as an "emergency" option (since I regularly had a hired baby-sitter for these situations) but that I considered perfectly trustworthy and that only helped strengthen our relationship.

So far I have discussed, based on my own experience and that of other research colleagues, two roles ethnographers' children can play in the research process: facilitating access to children and projecting positive identities on the adult. To close this section I want to point out a third role that other anthropologists have also discussed in relation to ethnographic work with children, and which is possible with older (adolescent) children: offspring as research collaborators. Lourdes de León, a Mexican linguistic anthropologist who has worked for over two decades with Mexican Mayan children and families, has explicitly discussed the role her own daughter (now an anthropology student herself) played in the research process (personal communication, December 12, 2007) and eventually made her contribution explicit by dedicating a recent monograph to her and acknowledging her collaboration in the study:

Isa, an excellent field collaborator, was an invaluable bridge to communicate with the children. I thank her for the years of her childhood she spent with me and with the Vázquez family, sometimes interrupting videos and tapes to 
demand attention, sometimes simply filming, sometimes playing with the children under study or simply giving her opinion about my failed work techniques. This book is for you, dear Isa. (De León 2005:16, translated from Spanish)

To summarise, researcher's children can play several other roles in the research study while not being the principal study participants. Based on my own fieldwork and the experience from other colleagues I have presented three roles that also have important implications for the fieldworker's identity: (a) offspring as a resource to access children, (b) parenthood as a resource for negotiations with adult gatekeepers, (c) offspring as research collaborators. These roles are only possible in ethnographic research enterprises, yet seem to have been neglected in the literature in favour of other configurations. In the conclusion I return to some of the more general questions that can be put forward from these experiences.

\section{Conclusion}

Researcher's children often seem to be present in some way in the field, but considerations about their contribution are often addressed in the more anecdotal (although not irrelevant) parts of the ethnographic text such as acknowledgments, the afterword, footnotes or personal conversations about fieldwork experiences. Yet these are probably the roles that are crucially important in ethnography, which is characterised by intense social and personal commitments. At the very least, the consideration of these "other roles" as a substantial conceptual problem is only relevant within an ethnographic framework, since in other research traditions once it has been decided that offspring will not be direct participants/subjects the paternal or maternal role of the researcher becomes irrelevant. The experiences I have presented suggest that the configurations that are opened up by the researcher's own children should be discussed and examined much more systematically in the future. This paper is only one first invitation, but to close the discussion I would like to point out some of the ethical implications these roles and relationships may have.

As pointed out above, ethical factors are central in discussions about the place researchers' children should occupy in the research enterprise. While the argument against studying one's own children directly may seem compelling, it is worth asking: What is lost if researchers' children are not allowed to have a role in or experience their parents' research? Research (or academic life more generally) and, as said, especially ethnographic research, is an intense, emotionally and time consuming experience that encompasses many facets of researchers' lives, both professional and private (Aull Davies 1999). If the topic involves children/childhood, what I find ethically questionable is, in fact, to completely bar one's children from this endeavour. From the perspective of the researcher's child, it is problematic since they are excluded from an area of their parent's life which they know is time consuming and important to them - and which, therefore, children would usually want to be involved in it. From the perspective of the research participants, it can only raise suspicions, since it would be difficult to explain the moral standing of a researcher who wanted to study a group of children while avoiding his/her own offspring having any contact with these participants or their social circumstances. For example, Scheper-Hughes (1993) did not exclude her children from her fieldwork, which was conducted in extreme conditions of poverty and infant mortality in Brazil - even when, as the monograph reveals, at times this became an emotionally draining 
experience for her daughter. In all the examples I have presented, if anything, the experience seemed gratifying and pleasurable for the children, so there does not seem to be any reason to ban them from the research process. In any case, given that each study has its own particularities, the general point is that these dynamics must be examined and made explicit in any research project where this triangular relationship between researcher, his/her children and other child participants comes into play.

\section{References}

Abu-Lughod, Lila. 1988. Veiled sentiments: Honor and poetry in a Bedouin society. California: University of California Press.

Adler, Patricia and Peter Adler. 1996. Parent-as-researcher: The politics of researching in the personal life. Qualitative Sociology 19(1), 35-58.

Aull Davies, Charlotte. 1999. Reflexive ethnography: A guide to researching selves and others. London: Routledge.

Bradley, Ben. 1989. Visions of infancy: A critical introduction to child psychology. Oxford: Blackwell.

Christensen, Pia and Allison James, eds. 2000. Research with children: Perspectives and practice. London: Falmer Press.

Corsaro, William. 2005. The sociology of childhood, 2nd edition. London: Pine Forge Press.

De León, Lourdes. 2005. La llegada del alma: Lenguaje, infancia y socialización entre los Mayas de Zinacatán [The arrival of the soul: Language, childhood and socialisation among Zinacatan Mayas]. México D.F: CONACULTA-INAH.

Gopnik, Alison, Andrew Meltzoff and Patricia Kuhl. 1999. How babies think. London: Weidenfeld \& Nicolson.

Greene, Sheila and Diane Hogan, eds. 2005. Researching children's experience: Approaches and methods. London: Sage Publications.

Greenwood, Alice. 1998. Accommodating friends: Niceness, meanness and discourse norms. In Kids talk: Strategic language use in later childhood, eds. Susan M. Hoyle and Carolyn Temple Adger, 68-81. Oxford: Oxford University Press.

Hardman, Charlotte. 1973. Can there be an anthropology of children? Journal of the Anthropological Society of Oxford 4(2), 85-99.

Hoyle, Susan. 1998. Register and footing in role play. In Kids talk: Strategic language use in later childhood, eds. Susan M. Hoyle and Carolyn Temple Adger, 47-67. Oxford: Oxford University Press.

Ochs, Elionor and Bambi Schieffelin. 1984. Language acquisition and socialization: Three developmental stories and their implications. In Culture theory: Essays in mind, self and emotion, eds. Richard Shweder and Robert LeVine, 276-320. Cambridge: Cambridge University Press.

Okely, Judith. 1983. The Traveller-Gypsies. Cambridge: Cambridge University Press.

Poveda, David. 2006. Nombres y relaciones sociales: El grupo de iguales como comunidad interpretativa [Names and social relations: The peer group as an 
interpretive community]. Papeles de Trabajo sobre Cultura, Educación y Desarrollo Humano 2(3), 1-32 (http://www.uam.es/ptcedh).

Poveda, David and Teresa Marcos. 2005. The social organization of a "stone fight": Gitano children's interpretive reproduction of ethnic conflict. Childhood 12(3), 327-349.

Scheper-Hughes, Nancy. 1993. Death without weeping: The violence of everyday life in Brazil. Berkeley: University of California Press.

Weiner, Annette. 1988. The Trobrianders of Papua New Guinea. Belmont, CA: Thompson-Wadsworth.

\section{Acknowledgments}

I would like to thank Lourdes de León and José Luis Linaza for sharing their research experiences with me and for their comments on earlier drafts of this paper. I would also like to thank the two anonymous reviewers for their feedback.

\section{About the author}

David Poveda is a professor in the Department of Developmental and Educational Psychology of the Autonomous University of Madrid (Spain) and is also currently a distance postgraduate student in Social Anthropology at the University of Wales, Lampeter. He is interested in children's literacy and linguistic practices, socio-cultural diversity and education and urban childhoods. He can be contacted at david.poveda@uam.es 